\title{
A facile route for preparation of CdS nanoparticles
}

\author{
M. Maleki ${ }^{1}$, M. Sasani Ghamsari ${ }^{2}$, Sh. Mirdamadi ${ }^{1}$, R. Ghasemzadeh ${ }^{1}$ \\ ${ }^{1}$ Department of Metallurgy and Material Engineering, Iran University Science \& Technology \\ ${ }^{2}$ Solid State Laser Division, Laser Research Center, 11365-8486, Tehran, Iran \\ E-mail: msghamsari@yahoo.com
}

\begin{abstract}
CdS nanoparticles have been synthesized by a chemical reaction route using ethylenediamine as a complexing agent. The nanoparticles were characterized using techniques such as X-ray powder diffraction (XRD), scanning electron microscope (SEM), UV-VIS absorption spectroscopy, and photoluminescence spectroscopy. The absorption edge for the bulk hexagonal $\mathrm{CdS}$ is at $512 \mathrm{~nm}(2.42 \mathrm{eV})$. Comparing with the bulk $\mathrm{CdS}$, it is believed that the blue shift in the absorption peak was caused by the quantum confinement effect. Photoluminescence measurements indicate $\mathrm{CdS}$ nanoparticles show fluorescence band with a maximum close to $315 \mathrm{~nm}$.
\end{abstract}

Keywords: cadmium sulfide, nanoparticle, X-ray diffraction, absorption spectroscopy, photoluminescence spectroscopy.

Manuscript received 25.12.06; accepted for publication 26.03.07; published online 01.06.07.

\section{Introduction}

Nanocrystalline semiconductor materials such as $\mathrm{PbS}$ and CdS have attracted considerable attention due to their unique properties, which are not present in bulk materials [1-3]. These nanoparticles exhibit size dependent properties (size quantization effects) such as a blue shift of absorption onset, a change of electrochemical potential of band edge, and an enhancement of photocatalytic activities, with decreasing crystallite size [4]. CdS, in particular, have been extensively studied due to their potential applications such as field effect transistors, light emitting diodes, photocatalysis and biological sensors [4-6]. Many synthetic methods have been employed to prepare CdS nanoparticles including soft chemical reaction, solid-state reaction, sol-gel process, sonochemical preparation [7-8], microwave heating [9], photoetching [10] and reverse micelle [11]. In this investigation, we have developed a new method to produce $\mathrm{CdS}$ nanoparticles of small sizes using chemical reaction. The nanoparticles are synthesized by reaction of ethylenediamine $\left(\mathrm{C}_{2} \mathrm{H}_{8} \mathrm{~N}_{2}\right)$ aqueous solution of cadmium acetate dehydrate $\left(\mathrm{C}_{4} \mathrm{H}_{6} \mathrm{O}_{4} \mathrm{Cd} \cdot 2 \mathrm{H}_{2} \mathrm{O}\right)$ with $\mathrm{Na}_{2} \mathrm{~S}$. The asprepared particles were analyzed by $\mathrm{X}$-ray diffraction (XRD), scanning electron microscope (SEM), UV-VIS absorption spectroscopy, photoluminescence (PL) spectroscopy.

\section{Experiment}

Cadmium acetate dehydrate $\left(\mathrm{C}_{4} \mathrm{H}_{6} \mathrm{O}_{4} \mathrm{Cd}_{2} \mathrm{H}_{2} \mathrm{O}\right)$, ethylenediamine $\left(\mathrm{C}_{2} \mathrm{H}_{8} \mathrm{~N}_{2}\right)$ were obtained from Merck. Double distilled water and ethanol was used for washing the particles. A typical procedure for the $\mathrm{CdS}$ nanoparticles synthesis is as follows: appropriate amount of analytically pure $\mathrm{Cd}\left(\mathrm{CH}_{3} \mathrm{COO}\right)_{2} \cdot 2 \mathrm{H}_{2} \mathrm{O}$ was dissolved into a deaerated $35 \mathrm{~mol} \%$ aqueous solution of ethylenediamine in a flask at room temperature. Then under vigorous stirring, analytical pure $\mathrm{Na}_{2} \mathrm{~S}$ was quickly added to this solution, and a milk-white sol was formed soon. Next, the resultant milk-white sol was heated to $100{ }^{\circ} \mathrm{C}$, and kept on stirring at this temperature for about 6 hours until the milk white reaction mixture gradually turned to a yellow colour. The final product was then collected and washed with distilled water and ethanol.

The X-ray powder diffraction (XRD) pattern was recorded on Philips B.V (CuK- radiation $\lambda=0.154 \mathrm{~nm})$, employing scanning rate of $0.02 \mathrm{deg} / \mathrm{s}$ in $2 \theta$ range from 20 to $60^{\circ}$. The SEM images were recorded on Philips XL30 scanning electron microscope. The sample used for SEM observations were prepared by transferring the particles that at first was dispersed in the ethanol to the SEM stage. After allowing the evaporation of ethanol from the stage, the particles on the stage were coated with a thin layer of gold. UV-VIS absorption spectrum 
of the sample was recorded employing a double beam, Hitachi, Japan, applying quartz cuvettes of the optical path length $1 \mathrm{~cm}$. The PL spectrum was achieved using Hitachi X530 fluorescence spectrophotometer with a $220 \mathrm{~nm}$ excitation line.

\section{Results and discussion}

The UV-VIS absorption spectrum for the colloidal CdS nanoparticles is shown in Fig. 1. According to mass approximation method, the size of colloidal nanoparticles 3-4 $\mathrm{nm}$ has been estimated. The sample was dispersed in absolute ethanol by an ultrasonic disperser. The absorption edge for the bulk hexagonal $\mathrm{CdS}$ is at $512 \mathrm{~nm}(2.42 \mathrm{eV})$. Comparing with the bulk $\mathrm{CdS}$, it is believed that the blue shift in the absorption peak was obviously caused by the quantum confinement effect. The XRD pattern of the precipitated nanoparticles was illustrated in Fig. 2. It can be attributed to hexagonal CdS (JCPDS - file No. 10-0454). The broadened peaks are indicating that the sizes of the particles are in nanorange. In order to achieve more confirmative information, the Debye-Scherer formula [12]

$L=0.9 \lambda / B \cos \theta=34 \mathrm{~nm}$

has been applied to calculate the size of the nanoparticles. Here, $L$ is the coherent length, $\lambda$ is the wavelength of X-ray radiation, $B$ is the full-width at half-maximum (FMWH) of the peak, and $\theta$ is the angle of diffraction. In the case of spherical crystallites, the corresponding crystallite size of nanoparticles obtained in this way is $34 \mathrm{~nm}$ which confirms our findings in SEM image (Fig. 3).

Fig. 4 shows the PL emission spectrum of an absolute ethanol solution containing CdS nanoparticles that are obtained by the offered route. The pattern consists of one strong and narrow emission at $340 \mathrm{~nm}$

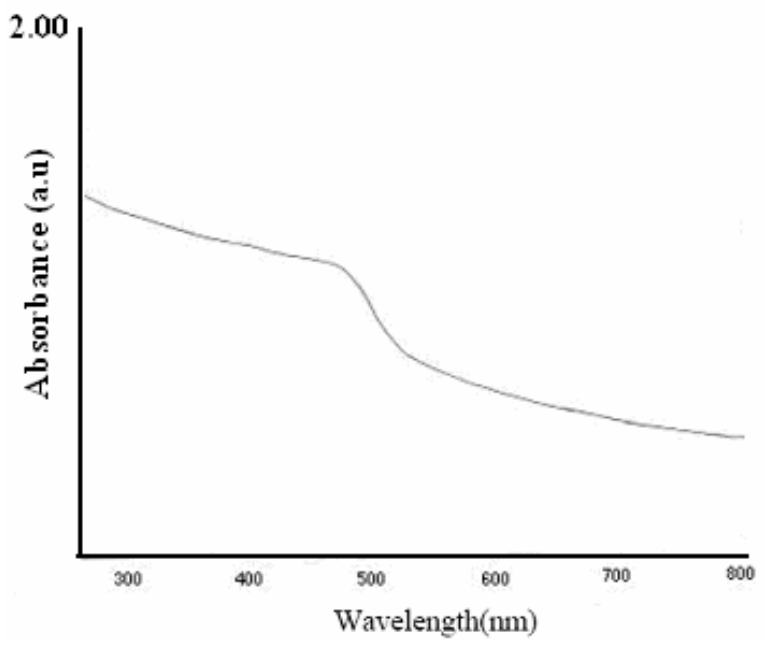

Fig. 1. UV-VIS absorption spectrum of CdS nanoparticles obtained by the offered route.

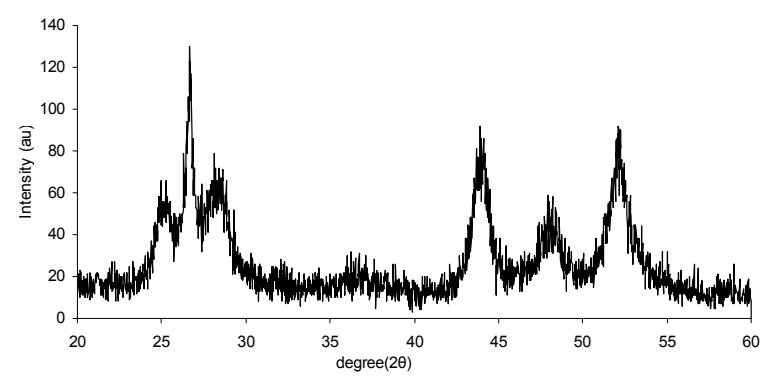

Fig. 2. XRD pattern of CdS nanoparticles.

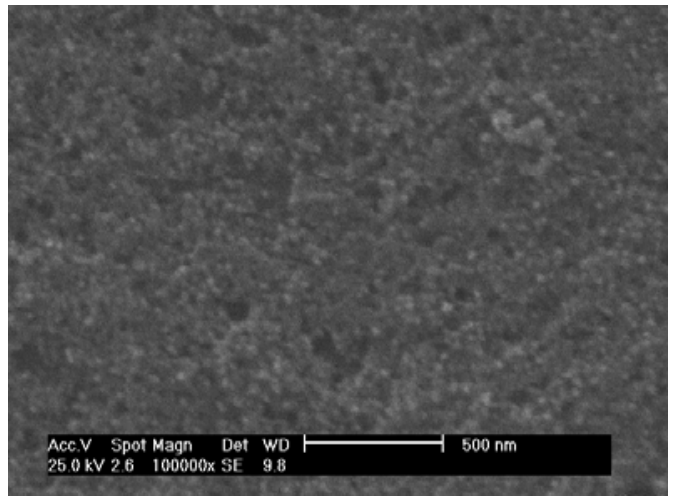

Fig. 3. SEM images of CdS nanoparticles prepared by the offered route.

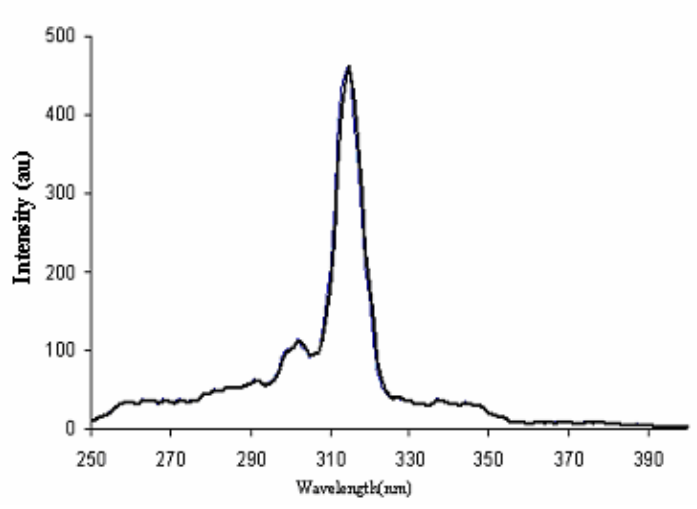

Fig. 4. Photoluminescence emission spectrum of $\mathrm{CdS}$ nanoparticles.

using a $220 \mathrm{~nm}$ excitation wavelength. The luminescence at $340 \mathrm{~nm}$ may be attributed to a higher level transition in $\mathrm{CdS}$ crystallites. It was reported that this kind of band-edge luminescence is caused by the recombination of excitons and/or shallowly trapped electron-hole pairs [13].

The apparent blue shift and the strong peak are also indicative of size quantization in as-prepared $\mathrm{CdS}$ nanoparticles. In our synthetic system, the investigations of $\mathrm{CdS}$ nanoparticles formation indicated that the nucleation and growth were well controlled. Firstly, 
ethylenediamine, as a strongly bidentating solvent, was ready to form relatively stable $\mathrm{Cd}^{2+}$ complexes $[14,15]$. Next, the $\mathrm{Na}_{2} \mathrm{~S}$ generate $\mathrm{S}^{2-}$ ions slowly and homogeneously. The $\mathrm{S}^{2-}$ ions will react with the $\mathrm{Cd}^{2+}$ ions that has chelated with ethylenediamine in a reversible and effective pathway to produce small $\mathrm{CdS}$ nanoparticles [16].

\section{Conclusions}

A simple method for preparation of $\mathrm{CdS}$ nanoparticles by using a chemical reaction has been described. The XRD pattern of CdS nanoparticles showed the materials to be of the nanometric size regime with a predominantly cubic phase. It was shown that the sizes of nanoparticles are $30-40 \mathrm{~nm}$. The CdS nanoparticles showed blue shift in their UV-VIS absorption band edge. The PL spectrum of CdS nanoparticles showed a fluorescence band with a maximum at about $315 \mathrm{~nm}$.

\section{References}

1. A. Henglein, Small-particle research: physicochemical properties of extremely small colloidal metal and semiconductor particles // Chem. Rev. 89, p. 1861-1873 (1989).

2. A. Fukuoka, Y. Sakamoto, S. Guan, S. Inagaki, N. Sugimoto, Y. Fukushima, K. Hirahara, S. Iijima, M. Ichikawa, Novel templating synthesis of necklace-shaped mono- and bimetallic nanowires in hybrid organic-inorganic mesoporous material // J. Amer. Chem. Soc. 123, p. 3373-3374 (2001).

3. C. Petit, M.P. Pilleni, Synthesis of cadmium sulfide in situ in reverse micelles and in hydrocarbon gels // J. Phys. Chem. 92, p. 2282-2286 (1988).

4. A.P. Alivisatos, Semiconductor clusters, nanocrystals, and quantum dots // Science 271, p. 933-937 (1996).
5. V.L. Kolvin, M.C. Schlamp, A.P. Alivisatos, Light emitting diodes made from cadmium selenide nanocrystals and a semiconducting polymer // Nature 370, p. 354-357 (1994).

6. D.L. Klein, R. Roth, A.K.L. Lim, A.P. Alivisatos, A single-electron transistor made from a cadmium selenide nanocrystal // Nature 389, p. 699-701 (1997).

7. R.S. Mane, C.D. Lokhande, Chemical deposition method for metal chalcogenide thin films // Mater. Chem. Phys. 65, p 1-31 (2000).

8. G. Henshaw, I.P. Oarkin, G. Shaw, Convenient, low-energy synthesis of metal sulfides and selenides; $\mathrm{PbE}, \mathrm{Ag}_{2} \mathrm{E}, \mathrm{ZnE}, \mathrm{CdE}(\mathrm{E}=\mathrm{S}, \mathrm{Se}) / /$ Chem. Communs 27, p. 1095-1096 (1996).

9. Y. Wada, H. Kuramoto, J. Anand, T. Tikamura, T. Sakata, H. Mori, S. Yanagida, Microwaveassisted size control of CdS nanocrystallites // J. Mater. Chem. 11, p. 1936-1940 (2001).

10. T. Torimoto, H. Kontani, Y. Shibutani, S. Kuwabata, T. Sakata, H. Mori, H. Yoneyama // J. Phys. Chem. 105, 6838 (2001).

11. A. Guinier, X-ray diffraction. Freeman, San Francisco, CA, 1963.

12. L. Sapanhel, M.A. Anderson, Synthesis of porous quantum-size cadmium sulfide membranes: photoluminescence phase shift and demodulation measurements // J. Amer. Chem. Soc. 112, p. 2278-2284 (1990).

13. W. Wang, Y. Geng, P. Yan, F. Liu, Y. Xie, Y. Qian, Preparation and characterization of CdS nanoparticles by ultrasonic irradiation // Inorg. Chem. Communs 4, p. 208-210 (2001).

14. X. Ge, Y. Ni, H. Liu, Q. Ye, Z. Zhang, $\gamma$-irradiation preparation of cadmium selenide nanoparticles in ethylenediamine system // Mater. Res. Bull. 36, p. 1609-1613 (2001).

15. X. Guo-yue, W. Han, C. Chuan-wei, Synthesis of single crystalline $\mathrm{CdS}$ nanowires with polyethylene glycol 400 as inducing template // Nonferrous Met. Soc., China, 16, p. 105-109. (2006) 